\title{
Acute left ventricular dysfunction secondary to right ventricular septal pacing in a woman with initial preserved contractility: a case report
}

\author{
Sana Ouali*, Soufiene Azzez, Slim Kacem, Afef Lagren, Elyes Neffeti, Rim Gribaa, Fahmi Remedi and
} Essia Boughzela

\begin{abstract}
Introduction: Right ventricular apical pacing-related heart failure is reported in some patients after long-term pacing. The exact mechanism is not yet clear but may be related to left ventricular dyssynchrony induced by right ventricular apical pacing. Right ventricular septal pacing is thought to deteriorate left ventricular function less frequently because of a more normal left ventricular activation pattern.

Case presentation: We report the case of a 55-year-old Tunisian woman with preserved ventricular function, implanted with a dual-chamber pacemaker for complete atrioventricular block. Right ventricular septal pacing induced a major ventricular dyssynchrony, severe left ventricular ejection fraction deterioration and symptoms of congestive heart failure. Upgrading to a biventricular device was associated with a decrease in the symptoms and the ventricular dyssynchrony, and an increase of left ventricular ejection fraction.

Conclusion: Right ventricular septal pacing can induce reversible left ventricular dysfunction and heart failure secondary to left ventricular dyssynchrony. This complication remains an unpredictable complication of right ventricular septal pacing.
\end{abstract}

\section{Introduction}

Right ventricular apical (RVA) pacing results in abnormal left ventricular (LV) electrical and mechanical activation and is associated with an increased risk of developing heart failure [1-3]. Right ventricular septal (RVS) pacing has been introduced to avoid this apparent and unpredictable complication of RVA pacing, because this pacing site appears to deliver a more physiological electrical activation of both ventricles, visible with a shorter paced QRS complex, than with RVA pacing $[4,5]$.

We report the case of a 55-year-old Tunisian woman with preserved ventricular function, implanted with a dual-chamber pacemaker for complete atrioventricular block. RVS pacing induced a major ventricular dyssynchrony, severe left ventricular ejection fraction deterioration and symptoms of congestive heart failure. Upgrading to a biventricular device was associated with a decrease

\footnotetext{
* Correspondence: sanaouali@hotmail.fr

Department of Cardiology. Sahloul Hospital, Sousse, Tunisia
}

in the symptoms and ventricular dyssynchrony, and increased left ventricular ejection fraction (LVEF).

\section{Case presentation}

A 55-year-old Tunisian woman presented with syncope. An electrocardiogram (ECG) upon admission showed complete heart block with a narrow QRS complex $(<120$ $\mathrm{ms}$ ) and an escape ventricular rate of $45 \mathrm{bpm}$. Our patient's medical history included arterial hypertension. She did not have diabetes mellitus, and had no family history of coronary artery disease. A two-dimensional echocardiography showed normal LV function with a $60 \% \mathrm{EF}$, the absence of significant valvulopathy and no regional wall motion abnormalities or pulmonary artery hypertension. A conventional dual chamber pacemaker (Medtronic; Sensia SEDR01, US) was implanted with the right ventricular (RV) lead positioned to her RV septum. The septal position was confirmed by fluoroscopic images; defined as a leftward orientation of the lead confirmed by $40^{\circ} \mathrm{left}$ anterior oblique projection [6]. The electrocardiographic criteria were defined as a negative deflection of lead I and 
positive initial $\mathrm{R}$-waves of the paced ventricular complex in lead ventricular fibrillation (VF) [7]. The pacemaker was programmed in a DDD mode with lower rate of $50 \mathrm{bpm}$ and upper tracking rate of $120 \mathrm{bpm}$. An ECG before discharge showed atrial synchronized ventricular pacing with a rate of $80 \mathrm{bpm}$ and QRS duration of $160 \mathrm{~ms}$ (Figure 1). Echocardiographic examination two days after pacemaker implantation demonstrated a normal LV function (55\%), a LV end-diastolic volume (LVEDV) of $84 \mathrm{~mL}$, the absence of significant valvulopathy and an aortic pre-ejection period (PEP) of $160 \mathrm{~ms}$. A ventricular dyssynchrony $(80 \mathrm{~ms}$ between septal and lateral electromechanical delays) was also measured with tissue Doppler imaging (TDI). The ratio of $\mathrm{E}$ (peak transmitral flow velocity in early diastole) to $\mathrm{Ea}$ (peak early diastolic myocardial velocity) velocity (E/ Ea) was estimated at 5.25. Our patient was readmitted seven months later with six days of progressive dyspnea (New York Heart Association (NYHA) class IV). Echocardiography showed severe LV akinesis, a depressed LVEF (28\%), a LVEDV of $153 \mathrm{~mL}$, the presence of significant mitral and tricuspid regurgitations (grade II-III), an aortic PEP of $170 \mathrm{~ms}$, pulmonary artery hypertension (50 $\mathrm{mmHg}$ ) and an E/Ea ratio of 6 . Her troponin level was not raised. Coronary angiography revealed the absence of significant obstructive epicardial coronary artery disease (Figure 2) and left ventriculography demonstrated depressed LVEF (25\%).

Despite instauration of optimal medical therapy, our patient remained at NYHA functional class III. She was upgraded to a cardiac resynchronization therapy (CRT)device with implantation of a lateral left ventricular lead (Figure 3). After one month of CRT, symptoms and exercise tolerance improved markedly from NYHA class III to class II. A twelve-lead ECG showed QRS shortening after CRT (Figure 4).

After one month, an echocardiography showed a decrease in the aortic PEP (130 ms), LV reverse remodeling, with a reduction of the LVEDV from $153 \mathrm{~mL}$ to $135 \mathrm{~mL}$, and significant improvement in LVEF to $40 \%$.
She had no symptoms of heart failure or syncope afterwards and device interrogation showed that her cumulative biventricular pacing was $100 \%$.

\section{Discussion}

Pacing from RVS sites has been suggested as an alternative to RVA pacing in an attempt to avoid long-term adverse consequences on LV function [4]. This case illustrated the rare phenomenon of rapid development of heart failure and dramatic decrease of LVEF after short-term RVS pacing for a complete atrioventricular block in a woman with initially preserved LVEF. This case also showed the reversible nature of RVS pacing-induced heart failure, and that it may be related to the reversible LV dyssynchrony induced by RVS pacing, as demonstrated by TDI and an aortic PEP of $160 \mathrm{~ms}$. There seems to be no other cause to account for the heart failure in this woman except for RVS pacing.

There is an increasing body of literature in which the authors investigate the acute and chronic effects of RVS pacing on electrical and mechanical synchrony, systolic and diastolic ventricular function and cardiovascular morbidity and mortality. Alternative RV pacing sites appear advantageous when compared to RVA pacing but their superiority has not been uniformly proven.

Ten Cate et al. [8] have demonstrated that acute abnormal LV activation either forms RVA or RV outflow tract (RVOT) pacing, resulting in an acute diminished LV function as assessed with echocardiographic wall motion score, traced LVEF, electromechanical delay and regional longitudinal LV strain. The authors have suggested that any RV pacing sites can negatively affect LV function and that readily available and non-invasive echocardiographic techniques are not helpful to guide the selection of the individual optimum pacing site during implantation. In the same way, Ng et al. [9] demonstrated that standard fluoroscopic and electrocardiographic implantation techniques for RVS pacing resulted in a heterogenous group of

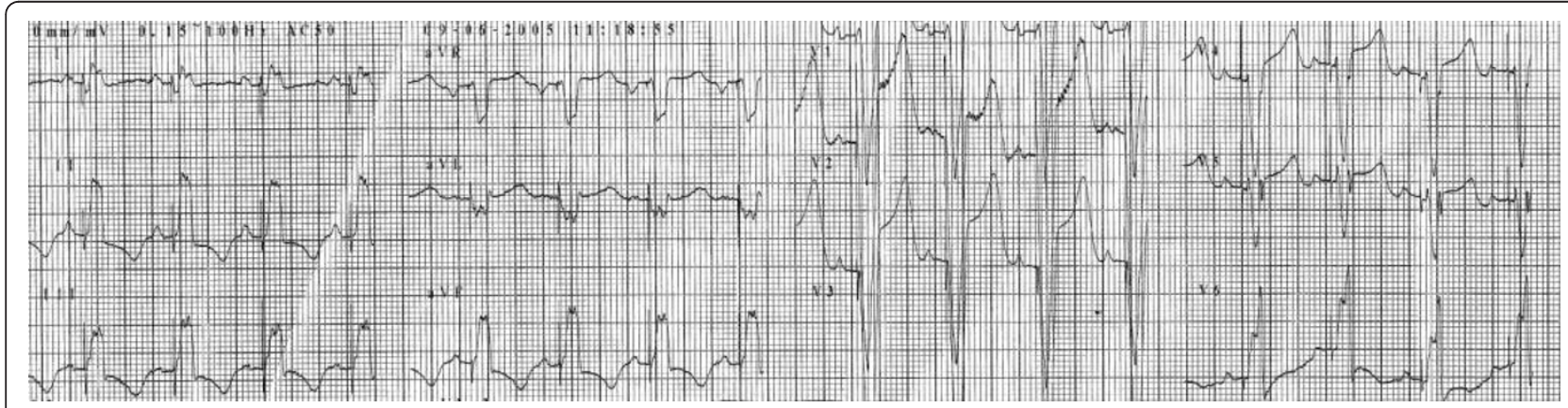

Figure 1 Twelve lead ECG after DDD pacemaker implantation. Note the QRS morphology with negative deflection of lead I and positive initial R-waves of the paced ventricular complex in lead aVF. 


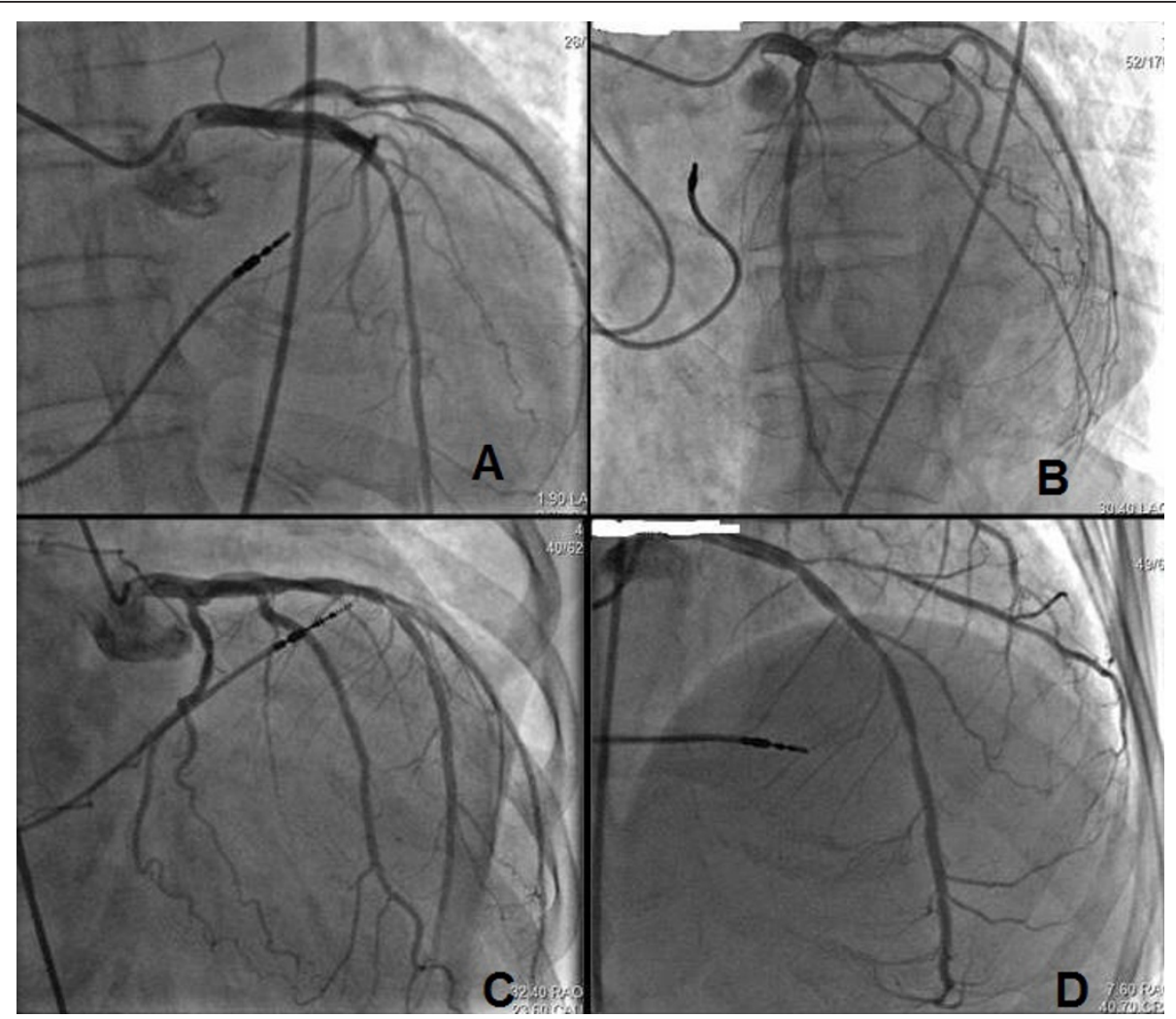

Figure 2 Coronary angiogram of the left coronary artery. Fluoroscopic images at an anteroposterior (AP, Panel A), left anterior oblique (LAO, Panel B), right anterior oblique (RAO, Panel C) and cranial (Cranial, Panel D) projection, showing the position of the active ventricular pacing lead at the RV septal region (arrow). Note the proximity of the septal lead tip to the left anterior descending artery.

different pacing sites. They found that the patients with RVS pacing had a lower LVEF, lower circumferential strain and greater circumferential dyssynchrony than those patients with RVA pacing, despite achieving a narrower QRS complex. They concluded that these detrimental effects associated with RVS pacing might have resulted from the heterogeneity of the real pacing sites included under the umbrella of the RVS pacing concept.

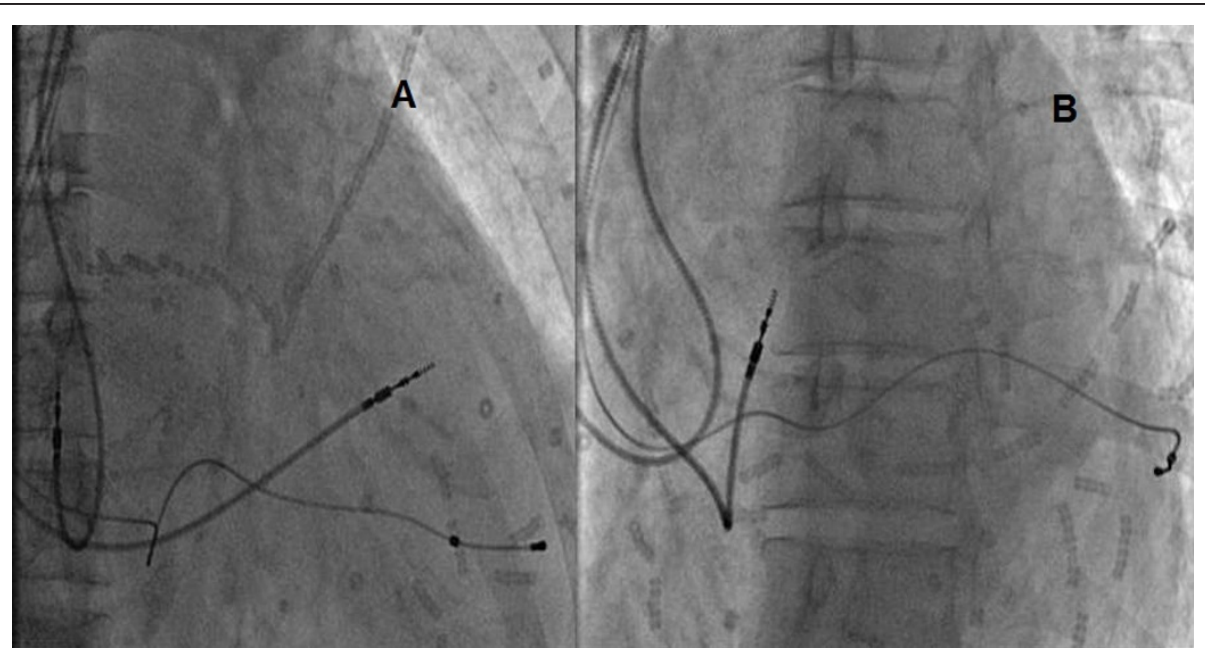

Figure 3 Anteroposterior (AP, Panel A) and left anterior oblique (LAO, Panel B) fluoroscopic projections showing leads position after CRT. 


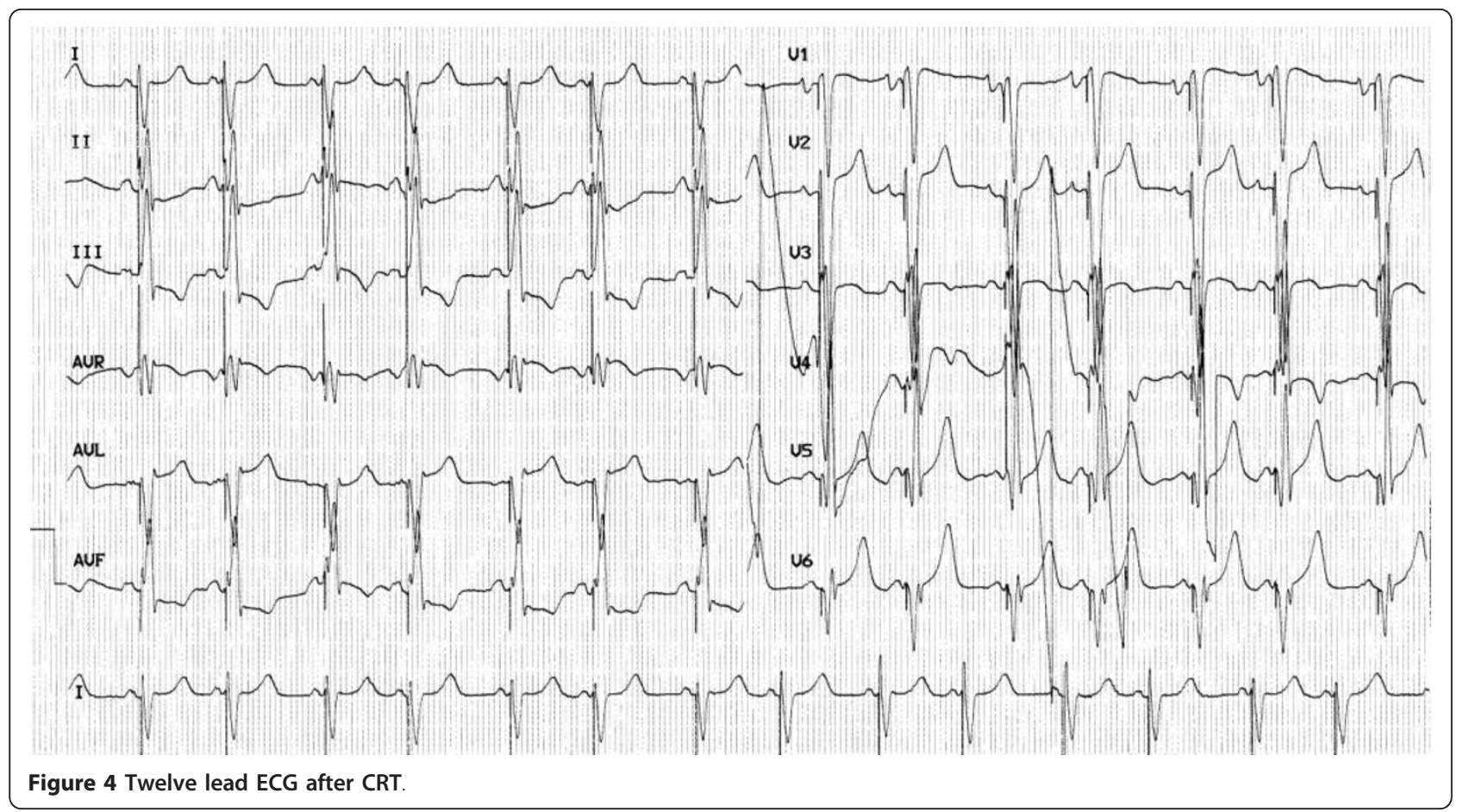

In patients with standard indications for pacing, the prediction of heart failure is difficult and the exact mechanism of RV pacing-related heart failure is not clear but may be related to LV dyssynchrony induced by RV pacing [10]. The best treatment option for these patients remains to be determined. CRT seems to be superior to RV pacing in patients with either impaired [11] or preserved LV systolic function [12] and standard pacing indication.

The Pacing to Avoid Cardiac Enlargement study [12] showed that the mean LVEF declined by almost seven percentage points (from $61.5 \pm 6.6 \%$ to $54.8 \pm 9.1 \%$ ) in the first year of RVA pacing in patients with a normal ejection fraction. Among nine patients in whom the LVEF decreased to less than $45 \%$ at 12 months, eight (89\%) were in the RV pacing group. The authors suggest that the ejection fraction could decrease rapidly in vulnerable patients and that these patients might benefit even more from biventricular pacing [12].

\section{Conclusion}

RVS pacing can induce reversible LV dysfunction and heart failure secondary to LV dyssynchrony. This remains an unpredictable complication of RV pacing. It should be highlighted that not all patients develop LV dyssynchrony and new onset heart failure after RV pacing. Therefore, early predictive factors [13-15], such as dyssynchrony at the time of implantation, paced QRS width, age, presence of atrial fibrillation, concomitant coronary artery disease, compromised LVEF or antibody status, should be further evaluated. These factors may reveal the patients who are more prone to LV function deterioration and who are consequently better candidates for biventricular pacing.

\section{Consent}

Written informed consent was obtained from the patient for publication of this case report and any accompanying images. A copy of the written consent is available for review by the Editor-in-Chief of this journal.

\section{Authors' contributions}

SO was the major contributor in writing the manuscript. All authors read and approved the final manuscript.

\section{Competing interests}

The authors declare that they have no competing interests.

Received: 20 April 2011 Accepted: 25 October 2011 Published: 25 October 2011

\section{References}

1. Leclerca C, Gras D, Le Helloco A, Nicol L, Mabo P, Daubert C: Hemodynamic importance of preserving the normal sequence of ventricular activation in permanent cardiac pacing. Am Heart J 1995, 129:1133-1141.

2. Wilkoff BL, Cook JR, Epstein AE, Dual Chamber and WI Implantable Defibrillator Trial Investigators: Dual chamber pacing or ventricular backup pacing in patients with an implantable defibrillator: the Dual Chamber and VVI Implantable Defibrillator (DAVID) Trial. JAMA 2002, 288:3115-3123.

3. Tops LF, Suffoletto MS, Bleeker GB, Boersma E, van der Wall EE, Gorcsan J III, Schalij MJ, Bax JJ: Speckle-tracking radial strain reveals left ventricular dyssynchrony in patients with permanent right ventricular pacing. $J \mathrm{Am}$ Coll Cardiol 2007, 50(12):1180-1188.

4. Mond HG, Vlay SC: Pacing the right ventricular septum: time to abandon apical pacing. Pacing Clin Electrophysiol 2010, 33(11):1293-1297. 
5. Tse HF, Wong KK, Siu CW, Zhang XH, Ho WY, Lau CP: Upgrading pacemaker patients with right ventricular apical pacing to right ventricular septal pacing improves left ventricular performance and functional capacity. J Cardiovasc Electrophysiol 2009, 20(8):901-905.

6. McGavigan AD, Roberts-Thomson KC, Hillock RJ, Stevenson IH, Mond HG: Right ventricular outflow tract pacing: radiographic and electrocardiographic correlates of lead position. Pacing Clin Electrophysiol 2006, 29(10):1063-1068.

7. Lieberman R, Grenz D, Mond HG, Gammage MD: Selective site pacing: defining and reaching the s elected site. Pacing Clin Electrophysiol 2004, 27(6 Pt 2):883-886.

8. ten Cate TJ, Scheffer MG, Sutherland GR, Verzijlbergen JF, van Hemel NM: Right ventricular outflow and apical pacing comparably worsen the echocardioghraphic normal left ventricle. Eur J of Echocardiogr 2008, 9(5):672-677.

9. Ng AC, Allman C, Vidaic J, Tie H, Hopkins AP, Leung DY: Long-term impact of right ventricular septal versus apical pacing on left ventricular synchrony and function in patients with second- or third-degree heart block. Am J Cardiol 2009, 103(8):1096-1101.

10. Fung JW, Zhang Q, Yip GW, Yu CM: Reversible left ventricular dyssynchrony and heart failure induced by right ventricular pacing. Int J Cardiol 2009, 134(1):117-119.

11. Höijer CJ, Meurling C, Brandt J: Upgrade to biventricular pacing in patients with conventional pacemakers and heart failure: a double-blind, randomized crossover study. Europace 2006, 8(1):51-55.

12. Yu CM, Chan JY, Zhang Q, Omar R, Yip GW, Hussin A, Fang F, Lam KH, Chan HC, Fung JW: Biventricular pacing in patients with bradycardia and normal ejection fraction. N Engl J Med 2009, 361(22):2123-2134.

13. Zhang XH, Chen H, Siu CW, Yiu KH, Chan WS, Lee KL, Chan HW, Lee SW, Fu GS, Lau CP, Tse HF: New-onset heart failure after permanent right ventricular apical pacing in patients with acquired high-grade atrioventricular block and normal left ventricular function. J Cardiovasc Electrophysiol 2008, 19(2):136-141.

14. Siu CW, Wang M, Zhang XH, Lau CP, Tse HF: Analysis of ventricular performance as a function of pacing site and mode. Prog Cardiovasc Dis 2008, 51(2):171-182.

15. Sagar S, Shen WK, Asirvatham SJ, Cha YM, Espinosa RE, Friedman PA, Hodge DO, Munger TM, Porter CB, Rea RF, Hayes DL, Jahangir A: Effect of long-term right ventricular pacing in young adults with structurally normal heart. Circulation 2010, 121(15):1698-1705.

doi:10.1186/1752-1947-5-524

Cite this article as: Ouali et al: Acute left ventricular dysfunction secondary to right ventricular septal pacing in a woman with initial preserved contractility: a case report. Journal of Medical Case Reports 2011 5:524.

\section{Submit your next manuscript to BioMed Central and take full advantage of:}

- Convenient online submission

- Thorough peer review

- No space constraints or color figure charges

- Immediate publication on acceptance

- Inclusion in PubMed, CAS, Scopus and Google Scholar

- Research which is freely available for redistribution 